\title{
Thermal diffusivity measurement for p-Si and Ag/p-Si by photoacoustic technique
}

\begin{abstract}
Thermal diffusivity (TD) of $\mathrm{p}-\mathrm{Si}$ and $\mathrm{Ag} / \mathrm{p}-\mathrm{Si}$ samples were measured by photoacoustic technique using open photoacoustic cell (OPC). The samples were annealed by heating them at $960,1050,1200$, and $1300{ }^{\circ} \mathrm{C}$ for $3 \mathrm{~h}$ in air. The thermal diffusivity of $\mathrm{Ag}$-coated samples was obtained by fitting the photoacoustic experimental data to the thermally thick equation for Rosencwaig and Gersho (RG) theory. For the single layer samples, the thermal diffusivity can be obtained by fitting as well as by obtaining the critical frequency $\mathrm{f} \mathrm{c}$. In this study, the thermal diffusivity of the $\mathrm{p}-\mathrm{Si}$ samples increased with increasing the annealing temperature. The thermal diffusivity of the $\mathrm{Ag} / \mathrm{p}-\mathrm{Si}$ samples, after reaching the maximum value of about $2.73 \mathrm{~cm} 2 / \mathrm{s}$ at a temperature of $1200{ }^{\circ} \mathrm{C}$, decreased due to the silver complete melt in the surface of the silicon.
\end{abstract}

